\title{
Common Fixed Point Theorems for Totally Quasi-G-Asymptotically Nonexpansive Semigroups with the Generalized f-Projection
}

\author{
Chunjie Wang, Yuanheng Wang* \\ Department of Mathematics, Zhejiang Normal University, Jinhua, China \\ Email: chunjwang@sina.cn, ${ }^{*}$ wangyuanhengmath@163.com
}

Received July 17, 2013; revised August 17, 2013; accepted August 24, 2013

Copyright (C) 2014 Chunjie Wang, Yuan-Heng Wang. This is an open access article distributed under the Creative Commons Attribution License, which permits unrestricted use, distribution, and reproduction in any medium, provided the original work is properly cited. In accordance of the Creative Commons Attribution License all Copyrights (C) 2014 are reserved for SCIRP and the owner of the intellectual property Chunjie Wang, Yuanheng Wang. All Copyright (C 2014 are guarded by law and by SCIRP as a guardian.

\section{ABSTRACT}

In this paper, we introduce some new classes of the totally quasi-G-asymptotically nonexpansive mappings and the totally quasi-G-asymptotically nonexpansive semigroups. Then, with the generalized f-projection operator, we prove some strong convergence theorems of a new modified Halpern type hybrid iterative algorithm for the totally quasi-G-asymptotically nonexpansive semigroups in Banach space. The results presented in this paper extend and improve some corresponding ones by many others.

\section{KEYWORDS}

Totally Quasi-G-Asymptotically Nonexpansive Semigroup; Generalized f-Projection Operator; Modified Halpern Type Hybrid Iterative Algorithm; Strong Convergence Theorem

\section{Introduction}

In this paper, we denote by $\mathbb{R}$ and $\mathbb{N}$ the set of real number and the set of nature number respectively. Let $E$ be a real Banach space with its dual $E^{*}$ and $C$ be a nonempty, closed and convex subset of $E$. The mapping $J: E \rightarrow 2^{E^{*}}$ is the normalized duality mapping, defined by

$$
J(x)=\left\{x^{*} \in E^{*}:\left\langle x, x^{*}\right\rangle=\|x\| \cdot\left\|x^{*}\right\|,\|x\|=\left\|x^{*}\right\|\right\}, x \in E
$$

Recall that a mapping $T: C \rightarrow C$ is said to be nonexpansive [1,2], if for each $x, y \in C$,

$$
\|T x-T y\| \leq\|x-y\| .
$$

A mapping $T: C \rightarrow C$ is said to be totally asymptotically nonexpansive, if there exists nonnegative real sequences $\left\{\mu_{n}\right\}$ and $\left\{v_{n}\right\}$ with $\mu_{n} \rightarrow 0, v_{n} \rightarrow 0$ as $(n \rightarrow \infty)$ and a strictly increasing continuous function $\varphi: \mathbb{R}^{+} \rightarrow \mathbb{R}^{+}$with $\varphi(0)=0$, such that for each $x, y \in C$,

$$
\left\|T^{n} x-T^{n} y\right\| \leq\|x-y\|+v_{n} \varphi(\|x-y\|)+\mu_{n}, \forall n \geq 0 .
$$

We use $\phi: E \times E \rightarrow \mathbb{R}^{+}$to denote the Lyapunov function defined by

$$
\phi(x, y)=\|x\|^{2}-2\langle x, J y\rangle+\|y\|^{2}, \forall x, y \in E .
$$

Obviously, we have

"Corresponding author. 


$$
(\|x\|-\|y\|)^{2} \leq \phi(x, y) \leq(\|y\|+\|x\|)^{2} .
$$

Recently, Chang et al. [3-5] and Li [6] introduced the uniformly totally quasi- $\phi$-asymptotically nonexpansive mappings and studied the strong convergence of some iterative methods for the mappings in Banach space.

Definition 1.1 [1] A countable family of mapping $\left\{T_{i}\right\}$ is said to be uniformly totally quasi- $\phi$-asymptotically nonexpansive, if $\bigcap_{n=1}^{\infty} F\left(T_{i}\right) \neq \varnothing$, and there exist nonnegative sequences $\left\{\mu_{n}\right\},\left\{v_{n}\right\}$ with $\mu_{n} \rightarrow 0, v_{n} \rightarrow 0$ (as $n \rightarrow \infty$ ) and a strictly increasing continuous function $\psi: \mathbb{R}^{+} \rightarrow \mathbb{R}^{+}$with $\psi(0)=0$, such that for each $i \geq 0$, and each $x \in C, p \in \bigcap_{n=1}^{\infty} F\left(T_{i}\right)$,

$$
\phi\left(p, T_{i} x\right) \leq \phi(p, x)+\mu_{n} \psi(\phi(p, x))+v_{n} .
$$

More recently, Wang et al. [7] studied the strong convergence for a countable family of total quasi- $\phi$ asymptotically nonexpansive mappings by using the hybrid algorithm in 2-uniformly convex and uniformly smooth real Banach spaces. Quan et al. [8] introduced total quasi- $\phi$-asymptotically nonexpansive semigroup containing many kinds of generalized nonexpansive mappings as its special cases and used the modified Halpern-Mann iteration algorithm to prove strong convergence theorems in Banach spaces.

We use $F(\mathscr{T})$ to denote the common fixed point set of the semigroup $\mathscr{T}$, i.e. $F(\mathscr{T})=\bigcap_{t \geq 0} F(T(t))$.

Definition 1.2 [8] One-parameter family $\mathscr{T}:=\{T(t): C \rightarrow C, t \geq 0\}$ is said to be a quasi- $\phi$-asymptotically nonexpansive semigroup, if $F(\mathscr{T}) \neq \varnothing$ and the following conditions are satisfied:

(a) $T(0) x=x$ for each $x \in C$;

(b) For each $x \in C, T(s+t) x=T(s) T(t) x, \forall t, s \in \mathbb{R}^{+}$;

(c) For each $x \in C$, the mapping $t \rightarrow T(t) x$ is continuous;

(d) For each $x \in C, p \in F(\mathscr{I})$, there exists a sequences $\left\{k_{n}\right\} \subset[1,+\infty)$ with $k_{n} \rightarrow 1$ as $n \rightarrow \infty$, such that

$$
\phi\left(p, T^{n}(t) x\right) \leq k_{n} \phi(p, x), \forall n \in \mathbb{N} .
$$

One-parameter family $\mathscr{T}:=\{T(t): C \rightarrow C, t \geq 0\}$ is said to be a totally quasi- $\phi$-asymptotically nonexpansive semigroup, if $F(\mathscr{T}) \neq \varnothing$, the conditions (a)-(c) and the following condition are satisfied:

(e) If $F(\mathscr{T}) \neq \varnothing$, there exist sequences $\left\{\mu_{n}\right\},\left\{v_{n}\right\}$ with $\mu_{n}, v_{n} \rightarrow 0$ as $n \rightarrow \infty$ and a strictly increasing continuous function $\psi: \mathbb{R} \rightarrow \mathbb{R}$ with $\psi(0)=0$, such that

$$
\phi\left(p, T^{n}(t) x\right) \leq \phi(p, x)+\mu_{n} \psi(\phi(p, x))+v_{n}, \forall n \in \mathbb{N},
$$

for all $x \in C, p \in F(\mathscr{T})$.

On the other hand, Wu et al. [9] introduced the generalized f-projection which extends the generalized projection and always exists in a real reflexive Banach space. Li et al. [10] proved some properties of the generalized f-projection operator and studied the strong convergence theorems for the relatively nonexpansive mappings.

In 2013, by using the generalized f-projection operator, Seawan et al. [11] introduced the modified Mann type hybrid projection algorithm for a countable family of totally quasi- $\phi$-asymptotically nonexpansive mappings in a uniformly smooth and strictly convex Banach space with Kadec-Klee property.

Motivated by the above researches, in this paper, we introduce a new class of the totally quasi-G-asymptotically nonexpansive mappings which contains the class of the totally quasi- $\phi$-asymptotically nonexpansive mappings and we extend from a countable family of mappings to the totally quasi-G-asymptotically nonexpansive semigroup. Then we modify the Halpern type hybrid projection algorithm by using the generalized f-projection operator for uniformly total quasi-G-asymptotically nonexpansive semigroup and prove some strong convergence theorems under some suitable conditions. The results presented in this paper extend and improve some corresponding ones by many others, such as $[1,2,7,8,10,11]$.

\section{Preliminaries}

This section contains some definitions and lemmas which will be used in the proofs of our main results in the 
next section.

Throughout this paper, we assume that $E$ be a real Banach space with its dual space $E^{*}$. A Banach space $E$ is said to be strictly convex, if $\frac{\|x+y\|}{2}<1$ for all $x, y \in E$ with $\|x\|=\|y\|=1$ and $x \neq y . E$ is said to be uniformly convex, if $\lim _{n \rightarrow \infty}\left\|x_{n}-y_{n}\right\|=0$ for any two sequences $\left\{x_{n}\right\},\left\{y_{n}\right\}$ in $E$ with $\left\|x_{n}\right\|=\left\|y_{n}\right\|=1$ and $\lim _{n \rightarrow \infty} \frac{\left\|x_{n}+y_{n}\right\|}{2}=1$. A Banach space $E$ is said to be smooth, if $\lim _{t \rightarrow 0} \frac{\|x+t y\|-\|x\|}{t}$ exists for each $x, y \in E$ with $\|x\|=\|y\|=1 . E$ is said to be uniformly smooth, if the limit is attainted uniformly for each $\|x\|=\|y\|=1$.

It is well known that the normalized dual mapping $J: E \rightarrow E^{*}$ holds the properties:

(1) If $E$ is a smooth Banach space, then $J$ is single-valued and semi-continuous;

(2) If $E$ is uniformly smooth Banach space, then $J$ is uniformly norm-to-norm continuous operator on each bounded subset of $E$.

A Banach space $E$ is said to have Kadec-Klee property, if for any sequence $\left\{x_{n}\right\} \in E$ satisfies $x_{n} \rightarrow x \in E$ and $\left\|x_{n}\right\| \rightarrow\|x\|$, then $x_{n} \rightarrow x$. As we all know, if $E$ is uniformly convex, then $E$ has the Kadec-Klee property.

Now, we give a functional $G: C \times E^{*} \rightarrow \mathbb{R} \bigcup\{+\infty\}$, defined by

$$
G\left(\xi, \eta^{*}\right)=\|\xi\|^{2}-2\left\langle\xi, \eta^{*}\right\rangle+\left\|\eta^{*}\right\|^{2}+2 \rho f(\xi)
$$

where $\xi \in C, \eta^{*} \in E^{*}, \rho$ is a positive real number and $f: C \rightarrow \mathbb{R} \cup\{+\infty\}$ is proper, convex and lower semi-continuous. From the definition of $G$ and $f$, it is easy to see the following properties:

(1) $G\left(\xi, \eta^{*}\right)$ is convex and continuous with respect to $\eta^{*}$ when $\xi$ is fixed;

(2) $G\left(\xi, \eta^{*}\right)$ is convex and lower semi-continuous with respect to $\xi$ when $\eta^{*}$ is fixed.

Definition 2.1 [9] $\prod_{C}^{f}: E^{*} \rightarrow 2^{C}$ is said to be a generalized f-projection operator, if for any $\eta^{*} \in E^{*}$,

$$
\prod_{C}^{f} \eta^{*}=\left\{u \in C: G\left(u, \eta^{*}\right)=\inf _{x \in C} G\left(x, \eta^{*}\right)\right\} .
$$

Lemma 2.2 [9] Let $E$ be a real reflexive Banach space with its dual $E^{*}, C$ be a nonempty closed and convex subset of $E$. Then $\prod_{C}^{f} y^{*}$ is a nonempty closed and convex subset of $C$ for all $y^{*} \in E^{*}$. Moreover, if $E$ is strictly convex, then $\prod_{C}^{f}$ is a single-valued mapping.

Recall that if $E$ is a smooth Banach space, then the normalized dual mapping $J$ is single-valued, i.e. there exists unique $\eta^{*} \in E^{*}$ such that $\eta^{*}=J x$ for each $x \in E$. Then (4) is equivalent to

$$
G(\xi, J x)=\|x\|^{2}-2\langle\xi, J x\rangle+\|J x\|^{2}+2 \rho f(\xi) .
$$

And in a smooth Banach space, the definition of the generalized f-projection operator transforms into:

Definition 2.3 [10] Let $E$ be a real smooth Banach space and $C$ be a nonempty, closed and convex subset of $E$. The mapping $\prod_{C}^{f}: E^{*} \rightarrow 2^{C}$ is called generalized f-projection operator, iffor all $x \in E$,

$$
\prod_{C}^{f} x=\left\{u \in C: G(u, J x)=\inf _{\xi \in C} G(\xi, J x)\right\}
$$

Now, we give the definition of the totally quasi- $G$-asymptotically nonexpansive mapping and the totally quasi- $G$-asymptotically nonexpansive semigroup.

Definition 2.4 A mapping $T: C \rightarrow C$ is said to be a quasi-G-asymptotically nonexpansive, if $F(T) \neq \varnothing$ and there exists a sequence $\left\{k_{n}\right\} \subset[1,+\infty]$ with $k_{n} \rightarrow 1$ (as $\left.n \rightarrow \infty\right)$, such that

$$
G\left(p, J T^{n} x\right) \leq k_{n} G(p, J x), \forall n \geq 0,
$$

for any $x \in C$ and $p \in F(T)$.

A mapping $T: C \rightarrow C$ is said to be a totally quasi-G-asymptotically nonexpansive, if $F(T) \neq \varnothing$ and there exist sequences $\left\{\mu_{n}\right\},\left\{\delta_{n}\right\}$ with $\mu_{n}, \delta_{n} \rightarrow 0$ as $n \rightarrow \infty$ and a strictly increasing continuous function 
$\tau: \mathbb{R} \rightarrow \mathbb{R}$ with $\tau(0)=0$, such that

$$
G\left(p, J T^{n} x\right) \leq G(p, x)+\mu_{n} \tau(G(p, J x))+\delta_{n}, \forall n \in \mathbb{N},
$$

for all $x \in C$ and $p \in F(T)$.

Remark 2.5 It is easy to see that a quasi- $\phi$-asymptotically nonexpansive mapping is a quasi-G-asymptotically nonexpansive mapping with $f(p)=0$ for all $p \in F(\mathscr{T})$. A totally quasi- $\phi$-asymptotically nonexpansive mapping is a totally quasi-G-asymptotically nonexpansive mapping with $\delta_{n}=\mu_{n} \psi(f(p))$. Therefore, our totally quasi-G-asymptotically nonexpansive mappings here are more widely than the totally quasi- $\phi$ asymptotically nonexpansive mappings which contain many kinds of generalized nonexpansive mappings as their special cases.

Definition 2.6 One-parameter family $\mathscr{T}:=\{T(t): C \rightarrow C, t \geq 0\}$ is said to be a quasi-G-asymptotically nonexpansive semigroup on $C$, if the conditions $(a)-(c)$ in Definition 1.2 and the following condition are satisfied:

(f) There exists a sequence $\left\{k_{n}\right\} \subset[1,+\infty]$ with $k_{n} \rightarrow 1$ as $n \rightarrow \infty$ such that

$$
G\left(p, T^{n}(t) x\right) \leq k_{n} G(p, J x)
$$

holds for all $x, y \in C, n \in \mathbb{N}$.

One-parameter family $\mathscr{T}:=\{T(t): C \rightarrow C, t \geq 0\}$ is said to be a totally quasi-G-asymptotically nonexpansive semigroup on $C$, if the above conditions (a)-(c) in Definition 1.2 and the following condition are satisfied:

(g) if $F(\mathscr{T}) \neq \varnothing$ and there exist sequences $\left\{\mu_{n}\right\},\left\{\delta_{n}\right\}$ with $\mu_{n}, v_{n} \rightarrow 0$ as $n \rightarrow \infty$ and a strictly increasing continuous function $\tau: \mathbb{R} \rightarrow \mathbb{R}$ with $\tau(0)=0$ such that for all $x \in C$ and $p \in F(\mathscr{T})$,

$$
G\left(p, J T^{n}(t) x\right) \leq G(p, J x)+\mu_{n} \tau(G(p, J x))+\delta_{n}
$$

holds for each $n \in \mathbb{N}$.

Remark 2.7 It is easy to see that a quasi- $\phi$-asymptotically nonexpansive semigroup is a quasi-G-asymptotically nonexpansive semigroup with $f(p)=0$ for all $p \in F(\mathscr{T})$. A totally quasi- $\phi$-asymptotically nonexpansive semigroup is a totally quasi-G-asymptotically nonexpansive semigroup with $\delta_{n}=\mu_{n} \psi(f(p))$. When we use $t_{m}\left(m \in \mathbb{N}^{+}\right)$instead of $t$ in Definition 2.6 and denote $T\left(t_{m}\right)$ by $T_{m}, \mathscr{T}:=\left\{T_{m}: C \rightarrow C\right\}_{m=1}^{\infty}$, then a quasi-G-asymptotically nonexpansive semigroup becomes a countable family of total quasi-G-asymptotically nonexpansive mappings which contains a countable family of total quasi- $\phi$-asymptotically nonexpansive mappings (see $[3,4,7]$ ) as it's special case. So our totally quasi-G-asymptotically nonexpansive semigroup here is the most widely family of the nonexpansive mappings so far.

The following Lemmas are necessary for proving the main results in this paper.

Lemma 2.8 [12] Let $E$ be a uniformly convex and smooth Banach space, and $\left\{x_{n}\right\},\left\{y_{n}\right\}$ be two sequences of E. If $\phi\left(x_{n}, y_{n}\right) \rightarrow 0$ and either $\left\{x_{n}\right\}$ or $\left\{y_{n}\right\}$ is bounded, then $\left\|x_{n}-y_{n}\right\| \rightarrow 0$.

Lemma 2.9 [13] If $E$ is a strictly convex, reflexive and smooth Banach space, then for $x, y \in E$, $\phi(x, y)=0$ if and only if $x=y$.

Lemma 2.10 [14] Let $E$ be a real Banach space and $f: E \rightarrow \mathbb{R} \bigcup\{+\infty\}$ be a lower semicontinuous convex functional. Then there exists $x^{*} \in E^{*}$ and $\alpha \in \mathbb{R}$ such that

$$
f(x) \geq\left\langle x, x^{*}\right\rangle+\alpha
$$

for each $x \in E$.

Lemma 2.11 [10] Let $E$ be a real reflexive and smooth Banach space and $C$ be a nonempty, closed and convex subset of $E$. Let $x \in E, \quad z \in \prod_{C}^{f} x$. Then

$$
\phi(y, z)+G(z, J x) \leq G(y, J x), \forall y \in C .
$$

Lemma 2.12 Let $E$ be a uniformly smooth and strictly convex Banach space, $C$ be a nonempty closed and convex subset of $E$. Let $T: C \rightarrow C$ be a totally quasi-G-asymptotically nonexpansive mapping defined by (9). If $\mu_{1}=\delta_{1}=0$, then the fixed point set $F(T)$ of $T$ is closed and convex subset of $C$. 
Proof Let $\left\{p_{n}\right\}$ be a sequence in $F(T)$ with $p_{n} \rightarrow p$ as $n \rightarrow \infty$, we prove that $p \in F(T)$. In fact, since $T$ is a quasi-G-asymptotically nonexpansive mapping, we have

$$
G\left(p_{n}, J T p\right) \leq G\left(p_{n}, J p\right)+\mu_{1} \tau\left(G\left(p_{n}, J p\right)\right)+\delta_{1} .
$$

Since $\mu_{1}=\delta_{1}=0$, it is equivalent to that

$$
\left\|p_{n}\right\|^{2}-2\left\langle p_{n}, J T p\right\rangle+\|J T p\|^{2}+2 \rho f\left(p_{n}\right) \leq\left\|p_{n}\right\|^{2}-2\left\langle p_{n}, J p\right\rangle+\|J p\|^{2}+2 \rho f\left(p_{n}\right) .
$$

So,

$$
\phi\left(p_{n}, T p\right) \leq \phi\left(p_{n}, p\right) \rightarrow 0 .
$$

By lemma 2.8, we have that $p \in F(T)$ which implies that $F(T)$ is closed. Next we prove that $F(T)$ is convex, i.e. for any $x, y \in F(T), \lambda \in(0,1)$, we prove that $z=\lambda x+(1-\lambda) y \in F(T)$. In fact,

$$
\begin{aligned}
& G\left(z, J T^{n} z\right)=\|z\|^{2}-2\left\langle z, J T^{n} z\right\rangle+\left\|J T^{n} z\right\|^{2}+2 \rho f(z) \\
& =\|z\|^{2}-2 \lambda\left\langle x, J T^{n} z\right\rangle-2(1-\lambda)\left\langle y, J T^{n} z\right\rangle+\left\|J T^{n} z\right\|^{2}+2 \rho f(z) \\
& =\|z\|^{2}+\lambda G(x, J z)+(1-\lambda) G\left(y, J T^{n} z\right)-\lambda\|x\|^{2}-(1-\lambda)\|y\|^{2} . \\
& \lambda G(x, J z)+(1-\lambda) G\left(y, J T^{n} z\right) \\
& \leq \lambda\left[G(x, J z)+\mu_{n} \tau(G(x, J z))+\delta_{n}\right]+(1-\lambda)\left[G(y, J z)+\mu_{n} \tau(G(y, J z))+\delta_{n}\right] \\
& =\lambda\left[\|x\|^{2}-2\langle x, J z\rangle+\|J z\|^{2}+2 \rho f(x)+\mu_{n} \tau(G(x, J z))+\delta_{n}\right] \\
& \quad+(1-\lambda)\left[\|y\|^{2}-2\langle y, J z\rangle+\|J z\|^{2}+2 \rho f(y)+\mu_{n} \tau(G(y, J z))+\delta_{n}\right] \\
& =\lambda\|x\|^{2}+(1-\lambda)\|y\|^{2}-\|z\|^{2}+2 \rho f(z)+\delta_{n} \\
& \quad+\lambda \mu_{n} \tau(G(x, J z))+(1-\lambda) \mu_{n} \tau(G(y, J z)) .
\end{aligned}
$$

Submitting (15) into (14), we have

$$
\phi\left(z, T^{n} z\right)=\|z\|^{2}-2\left\langle z, J T^{n} z\right\rangle+\left\|J T^{n} z\right\|^{2} \leq \lambda \mu_{n} \tau(G(x, J z))+(1-\lambda) \mu_{n} \tau(G(y, J z))+\delta_{n} .
$$

This implies that $T^{n} z \rightarrow z$ and $T^{n+1} z=T T^{n} z \rightarrow z$. Hence we have $z=T z$, i.e. $z \in F(T)$. This completes the proof of Lemma 2.12 .

\section{Main Results}

Theorem 3.1 Let $E$ be a uniformly convex and uniformly smooth Banach space and $C$ be a nonempty closed and convex subset of $E$. Let $f: E \rightarrow \mathbb{R}$ be a convex and lower semicontinuous function with $C \subset \operatorname{int}(D(f))$ such that $f(x)>0$ for all $x \in C$ and $f(0)=0$. Let $\mathscr{T}=\{T(t): C \rightarrow C, t \geq 0\}$ be a closed and totally quasi-G-asymptotically nonexpansive semigroup defined by Definition 2.6. Assume that $T(t)$ is uniformly asymptotically regular for all $t \geq 0$ and $F(\mathscr{T})=\bigcap_{t \geq 0} F(T(t)) \neq \varnothing$. Let the sequence $\left\{x_{n}\right\}$ be defined by

$$
\left\{\begin{array}{l}
x_{1} \in E, \text { chosen arbitrarily; } C_{1}=C, \\
y_{n, t}=J^{-1}\left[\alpha_{n} J x_{1}+\left(1-\alpha_{n}\right) J T^{n}(t) x_{n}\right], \\
C_{n+1}=\left\{z \in C_{n}: \sup _{t \geq 0} G\left(z, J y_{n, t}\right) \leq \alpha_{n} G\left(z, J x_{1}\right)+\left(1-\alpha_{n}\right) G\left(z, J x_{n}\right)+\xi_{n}\right\}, \\
x_{n+1}=\prod_{C_{n+1}}^{f} x_{1},
\end{array}\right.
$$


where $\xi_{n}=\mu_{n} \sup _{p \in F(\mathscr{F})} \tau\left(G\left(p, J x_{n}\right)\right)+\delta_{n}$ and the sequence $\left\{\alpha_{n}\right\} \subset(0,1)$. If $\lim _{n \rightarrow \infty} \alpha_{n}=0$ and $\mu_{1}=\delta_{1}=0$, then $\left\{x_{n}\right\}$ converges strongly to $\prod_{F(\mathscr{F})}^{f} x_{1}$.

Proof We divide the proof into five steps.

Step 1. Firstly, we prove that $F(\mathscr{T})$ and $C_{n}$ are closed and convex subsets in $C$.

Since $T(t)$ is a totally quasi-G-asymptotically nonexpansive mapping, it follows the Lemma 2.12 that $F(T(t))$ is a closed and convex subset of $C$. So $F(\mathscr{T})=\bigcap_{t \geq 0} F(T(t))$ is closed and convex subset of $C$.

Again, by the assumption, $C_{1}=C$ is closed and convex. Suppose that $C_{n}$ is the closed and convex subset of $C$ for $n \geq 2$. In view of the definition of $G$, we have that

$$
\begin{aligned}
C_{n+1} & =\left\{z \in C_{n}: \sup _{t \geq 0} G\left(z, J y_{n, t}\right) \leq \alpha_{n} G\left(z, J x_{1}\right)+\left(1-\alpha_{n}\right) G\left(z, J x_{n}\right)+\xi_{n}\right\} \\
& =\bigcap_{t \geq 0}\left\{z \in C_{n}: G\left(z, J y_{n, t}\right) \leq \alpha_{n} G\left(z, J x_{1}\right)+\left(1-\alpha_{n}\right) G\left(z, J x_{n}\right)+\xi_{n}\right\} \bigcap C_{n} \\
& =\bigcap_{t \geq 0}\left\{z \in C_{n}: 2\left\langle z, J x_{n}\right\rangle-J y_{n, t} \leq\left\|x_{n}\right\|^{2}-\left\|y_{n, t}\right\|^{2}+\xi_{n}\right\} \bigcap C_{n} .
\end{aligned}
$$

This shows that $C_{n+1}$ is closed and convex for all $n \geq 1$.

Step 2. Next, we prove that $F(\mathscr{T}) \subset C_{n}$.

In fact, $F(T) \subset C_{1}=C$. Suppose that $F(T) \subset C_{n}$, for some $n \geq 2$. Since $\mathscr{T}=\{T(t): C \rightarrow C, t \geq 0\}$ is a totally quasi-G-asymptotically nonexpansive semigroup, for each $p \in F(T) \subset C_{n}$, we have

$$
\begin{aligned}
G\left(p, y_{n, t}\right)= & G\left(p, \alpha_{n} J x_{1}+\left(1-\alpha_{n}\right) J T^{n}(t) x_{n}\right) \\
= & \|p\|^{2}-2\left\langle p, \alpha_{n} J x_{1}+\left(1-\alpha_{n}\right) J T^{n}(t) x_{n}\right\rangle+\left\|\alpha_{n} J x_{1}+\left(1-\alpha_{n}\right) J T^{n}(t) x_{n}\right\|^{2}+2 \rho f(p) \\
\leq & \|p\|^{2}-2 \alpha_{n}\left\langle p, J x_{1}\right\rangle-2\left(1-\alpha_{n}\right)\left\langle p, J T^{n}(t) x_{n}\right\rangle+\alpha_{n}\left\|J x_{1}\right\|^{2} \\
& +\left(1-\alpha_{n}\right)\left\|J T^{n}(t) x_{n}\right\|^{2}+2 \rho f(p) \\
= & \alpha_{n} G\left(p, J x_{1}\right)+\left(1-\alpha_{n}\right) G\left(p, J T^{n}(t) x_{n}\right) \\
\leq & \alpha_{n} G\left(p, J x_{1}\right)+\left(1-\alpha_{n}\right) G\left(p, J x_{n}\right)+\left(1-\alpha_{n}\right)\left(\mu_{n} \tau\left(G\left(p, J x_{n}\right)\right)+\delta_{n}\right) \\
\leq & G\left(p, J x_{1}\right)+\left(1-\alpha_{n}\right) G\left(p, J x_{n}\right)+\xi_{n},
\end{aligned}
$$

where $\xi_{n}=\mu_{n} \sup _{t \geq 0} \tau\left(G\left(p, J x_{n}\right)\right)+\delta_{n}$. This shows that $p \in C_{n+1}$, which implies that $F(\mathscr{T}) \subset C_{n}$ for all $n \geq 1$.

Step 3. We prove that $\left\{x_{n}\right\}$ is bounded and $\left\{G\left(x_{n}, x_{1}\right)\right\}$ is convergent.

Since $f: E \rightarrow \mathbb{R}$ is a convex and lower semicontinuous function, by virtue of Lemma 2.10, we have that there exists $x^{*} \in E^{*}$ and $\alpha \in \mathbb{R}$ such that $f(x) \geq\left\langle x, x^{*}\right\rangle+\alpha$ for each $x \in E$. Then for each $x_{n} \in E$, we have that

$$
\begin{aligned}
G\left(x_{n}, J x_{1}\right) & =\left\|x_{n}\right\|^{2}-2\left\langle x_{n}, J x_{1}\right\rangle+\left\|x_{1}\right\|^{2}+2 \rho f\left(x_{n}\right) \\
& \geq\left\|x_{n}\right\|^{2}-2\left\langle x_{n}, J x_{1}\right\rangle+\left\|x_{1}\right\|^{2}+2 \rho\left\langle x_{n}, x^{*}\right\rangle+2 \rho \alpha \\
& =\left\|x_{n}\right\|^{2}-2\left\langle x_{n}, J x_{1}-\rho x^{*}\right\rangle+\left\|x_{1}\right\|^{2}+2 \rho \alpha \\
& \geq\left\|x_{n}\right\|^{2}-2\left\|x_{n}\right\|\left\|J x_{1}-\rho x^{*}\right\|+\left\|x_{1}\right\|^{2}+2 \rho \alpha \\
& =\left(\left\|x_{n}\right\|-\left\|J x_{1}-\rho x^{*}\right\|\right)^{2}+\left\|x_{1}\right\|^{2}-\left\|J x_{1}-\rho x^{*}\right\|^{2}+2 \rho \alpha .
\end{aligned}
$$

Again since $x_{n}=\prod_{C_{n}}^{f} x_{1}$ and $F(\mathscr{T}) \subset C_{n}$, from Lemma 2.11, we have $G\left(x_{n}, J x_{1}\right) \leq G\left(p, J x_{1}\right)$ for any $p \in F(\mathscr{T})$. Hence, from (17), we have 


$$
G\left(p, J x_{1}\right) \geq G\left(x_{n}, J x_{1}\right) \geq\left(\left\|x_{n}\right\|-\left\|J x_{1}-\rho x^{*}\right\|\right)^{2}+\left\|x_{1}\right\|^{2}-\left\|J x_{1}-\rho x^{*}\right\|^{2}+2 \rho \alpha .
$$

Therefore $\left\{x_{n}\right\}$ and $\left\{G\left(x_{n}, J x_{1}\right)\right\}$ are bounded. As $x_{n+1}=\prod_{C_{n+1}}^{f} x_{1} \in C_{n+1} \subset C_{n}$ and $x_{n}=\prod_{C_{n}}^{f} x_{1}$, by using Lemma 2.11, we have that

$$
G\left(x_{n+1}, J x_{1}\right)-G\left(x_{n}, J x_{1}\right) \geq \phi\left(x_{n+1}, x_{n}\right) \geq 0 .
$$

This implies that $\left\{G\left(x_{n}, J x_{1}\right)\right\}$ is bounded and nondecreasing. Hence the $\operatorname{limit}_{\lim _{n \rightarrow \infty}} G\left(x_{n}, x_{1}\right)$ exists. Step 4. Next, we prove that $x_{n} \rightarrow \bar{x} \in F(\mathscr{F})$.

By the definition of $C_{n}$, for any positive integer $m \geq n$, we have $x_{m}=\prod_{C_{m}}^{f} x_{1} \in C_{m} \subset C_{n}$. Again from Lemma 2.11, we have that

$$
\phi\left(x_{m}, x_{n}\right)<=G\left(x_{m}, J x_{1}\right)-G\left(x_{n}, J x_{1}\right) \rightarrow 0
$$

as $m, n \rightarrow \infty$. It follows from Lemma 2.8 that $\lim _{n, m \rightarrow \infty}\left\|x_{m}-x_{n}\right\|=0$. Hence $\left\{x_{n}\right\}$ is a Cauchy sequence in $C$. Since $C$ is a nonempty closed and convex subset of Banach space $E$, we can assume that $x_{n} \rightarrow \bar{x} \in C$. Therefore, we have

$$
\lim _{n \rightarrow \infty} \xi_{n}=\lim _{n \rightarrow \infty}\left[\mu_{n} \sup _{p \in F(T)} \tau G\left(p, J x_{n}\right)+\mu_{n}\right]=0 .
$$

Since $x_{n+1} \in C_{n+1}$ and $\alpha_{n} \rightarrow 0$, it follows from the definition of $C_{n}$ that we have

$$
\begin{aligned}
& \sup _{t \geq 0} G\left(x_{n+1}, J y_{n, t}\right) \leq \alpha_{n} G\left(x_{n+1}, J x_{1}\right)+\left(1-\alpha_{n}\right) G\left(x_{n+1}, J x_{n}\right)+\xi_{n} . \\
& \left\|x_{n+1}\right\|^{2}-2\left\langle x_{n+1}, J y_{n, t}\right\rangle+\left\|y_{n, t}\right\|^{2}+2 \rho f\left(x_{n+1}\right) \\
& \leq \alpha_{n}\left(\left\|x_{n+1}^{2}-2\left\langle x_{n+1}, J y_{n, t}\right\rangle+\right\| x_{1} \|^{2}+2 \rho f\left(x_{n+1}\right)\right) \\
& +\left(1-\alpha_{n}\right)\left(\left\|x_{n+1}\right\|^{2}-2\left\langle x_{n+1}, J x_{n}\right\rangle+\left\|x_{n}\right\|^{2}+2 \rho f\left(x_{n+1}\right)+\xi_{n}\right) . \\
& \left\|x_{n+1}\right\|^{2}-2\left\langle x_{n+1}, J y_{n, t}\right\rangle+\left\|y_{n, t}\right\|^{2} \leq\left(1-\alpha_{n}\right)\left(\left\|x_{n+1}\right\|^{2}-2\left\langle x_{n+1}, J x_{n}\right\rangle+\left\|x_{n}\right\|^{2}\right) \\
& +\alpha_{n}\left(\left\|x_{n+1}^{2}-2\left\langle x_{n+1}, J y_{n, t}\right\rangle+\right\| x_{1} \|^{2}\right)+\xi_{n} .
\end{aligned}
$$

That is

$$
\phi\left(x_{n+1}, y_{n, t}\right) \leq \alpha_{n} \phi\left(x_{n+1}, x_{1}\right)+\left(1-\alpha_{n}\right) \phi\left(x_{n+1}, x_{1}\right)+\xi_{n} .
$$

Since $x_{n} \rightarrow u$ and $\alpha_{n} \rightarrow 0$, from (18), (19), we can get

$$
\lim _{n \rightarrow \infty} \phi\left(x_{n+1}, y_{n, t}\right)=0 .
$$

Then, by Lemma 2.8, we have

$$
\lim _{n \rightarrow \infty} y_{n, t}=\bar{x} .
$$

As $J$ is uniformly continuous on each bounded subset of $E$, we have $J x_{n} \rightarrow \sqrt{x}$. Then from (20), for any $t \geq 0$, we have

$$
\begin{aligned}
0 & =\lim _{n \rightarrow \infty}\left\|J y_{n, t}-\sqrt{x}\right\|=\lim _{n \rightarrow \infty}\left\|\alpha_{n} J x_{1}+\left(1-\alpha_{n}\right) J T^{n}(t) x_{n}-\sqrt{x}\right\| \\
& \geq \lim _{n \rightarrow \infty}\left[\left(1-\alpha_{n}\right)\left\|J T^{n}(t) x_{n}-J u\right\|-\alpha_{n}\left\|J x_{1}-\sqrt{x}\right\|\right] \\
& =\lim _{n \rightarrow \infty}\left(1-\alpha_{n}\right)\left\|J T^{n}(t) x_{n}-\sqrt{x}\right\| .
\end{aligned}
$$


Since $\lim _{n \rightarrow \infty}\left(1-\alpha_{n}\right)=1$, we have that

$$
\lim _{n \rightarrow \infty}\left\|J T^{n}(t) x_{n}-\sqrt{x}\right\|=0
$$

uniformly for all $t \geq 0$.

Since $J$ is uniformly continuous, we obtain that

$$
\lim _{n \rightarrow \infty}\left\|T^{n}(t) x_{n}-\bar{x}\right\|=0,
$$

uniformly for all $t \geq 0$.

Since $T(t)$ is asymptotically regular for all $t \geq 0$, from (21), we have

$$
\lim _{n \rightarrow \infty}\left\|T^{n+1}(t) x_{n}-\bar{x}\right\|=\lim _{n \rightarrow \infty}\left(\left\|T^{n+1}(t) x_{n}-T^{n}(t) x_{n}\right\|+\left\|T^{n}(t) x_{n}-\bar{x}\right\|\right)=0
$$

Then $T^{n+1}(t) x_{n}=T(t) T^{n}(t) x_{n} \rightarrow \bar{x}$ as $n \rightarrow \infty$. By virtue of the closedness of $T(t)$ and $T^{n}(t) x_{n} \rightarrow \bar{x}$ as $n \rightarrow \infty$, we can obtain that $T(t) \bar{x}=\bar{x}$, which implies $\bar{x} \in F(T(t))$ for all $t \geq 0$.

Hence, $x_{n} \rightarrow \bar{x} \in F(\mathscr{T})=\bigcap_{t \geq 0} F(T(t))$.

Step 5. Finally, we prove that $x_{n} \rightarrow \bar{x}=\prod_{F(\mathscr{F})}^{f} x_{1}$.

Since $F(\mathscr{T}) \subset C_{n} \subset E$ is closed and convex, by Lemma 2.2, we know that $\prod_{F(\mathscr{F})^{x_{1}}}^{f}$ is single-valued. Assume that $\varpi=\prod_{F(\mathscr{g})}^{f} x_{1}$. Since $\varpi \in F(\mathscr{T}) \subset C_{n}$ and $x_{n}=\prod_{C_{n}}^{f} x_{1}$, we have $G\left(x_{n}, J x_{1}\right) \leq G\left(\varpi, J x_{1}\right)$ for all $n \geq 1$. As we know, $G(y, J x)$ is convex and lower semicontinuous with respect to $\mathrm{y}$ when $\mathrm{x}$ is fixed. So we have

$$
G\left(\bar{x}, J x_{1}\right) \leq \liminf _{n \rightarrow \infty} G\left(x_{n}, J x_{1}\right) \leq \limsup _{n \rightarrow \infty} G\left(x_{n}, J x_{1}\right) \leq G\left(\varpi, x_{1}\right) .
$$

As $\bar{x} \in F(\mathscr{T})$, from the definition of $\prod_{F(\mathscr{F})^{x_{1}}}^{f}$, we can obtain that $\bar{x}=\varpi=\prod_{F(\mathscr{I})^{x_{1}}}^{f}$ and $x_{n} \rightarrow \bar{x}$ as $n \rightarrow \infty$. This completes the proof of Theorem 3.1.

Just as in Remark 2.7, we use $t_{m}\left(m \in \mathbb{N}^{+}\right)$instead of $t$ in Definition 2.6 and denote $T\left(t_{m}\right)$ by $T_{m}$, $\mathscr{T}:=\left\{T_{m}: C \rightarrow C\right\}_{m=1}^{\infty}$ becomes a countable family of total quasi-G-asymptotically nonexpansive mappings. Then we get the following corollary.

Corollary 3.2 Let $E$ be a uniformly convex and uniformly smooth Banach space and $C$ be a nonempty closed and convex subset of $E$. Let $\mathscr{T}:=\left\{T_{m}: C \rightarrow C\right\}_{m=1}^{\infty}$ be a countable family of closed and totally quasi-Gasymptotically nonexpansive mappings. Let $f: E \rightarrow \mathbb{R}$ be a convex and lower semicontinuous function with $C \subset \operatorname{int}(D(f))$ such that $f(x)>0$ for all $x \in C$ and $f(0)=0$. Assume that $T_{m}$ is uniformly asymptotically regular for all $m \in \mathbb{N}^{+}$and $F(\mathscr{T})=\bigcap_{m \in \mathbb{N}^{+}} F\left(T_{m}\right) \neq \varnothing$. Let the sequence $\left\{x_{n}\right\}$ defined by

$$
\left\{\begin{array}{l}
x_{1} \in E, \text { chosen arbitrarily; } C_{1}=C \\
y_{n, m}=J^{-1}\left[\alpha_{n} J x_{1}+\left(1-\alpha_{n}\right) J T_{m}^{n} x_{n}\right], \\
C_{n+1}=\left\{z \in C_{n}: \sup _{m \in \mathbb{N}^{+}} G\left(z, J y_{n, m}\right) \leq \alpha_{n} G\left(z, J x_{1}\right)+\left(1-\alpha_{n}\right) G\left(z, J x_{n}\right)+\xi_{n}\right\}, \\
x_{n+1}=\prod_{c_{n+1}}^{f} x_{1},
\end{array}\right.
$$

where, $\xi_{n}=\mu_{n} \sup _{p \in F(\mathscr{F})} \tau\left(G\left(p, J x_{n}\right)\right)+\delta_{n}$ and $\left\{\alpha_{n}\right\} \subset(0,1)$. If $\lim _{n \rightarrow \infty} \alpha_{n}=0$ and $\mu_{1}=\delta_{1}=0$, then $\left\{x_{n}\right\}$ converges strongly to $\prod_{F(\mathscr{F})^{x_{1}}}^{f}$.

In Corollary 3.2, when $f(x) \equiv 0$ for all $x \in C, \mathscr{T}=\left\{T_{m}: C \rightarrow C\right\}_{m=1}^{\infty}$ be a countable family of closed and totally quasi- $\phi$-asymptotically nonexpansive mappings. Then we can get the following theorem. 
Corollary 3.3 Let $E$ be a uniformly convex and uniformly smooth Banach space and $C$ be a nonempty closed and convex subset of $E$. Let $\mathscr{T}=\left\{T_{m}: C \rightarrow C\right\}_{m=1}^{\infty}$ be a countable family of closed and totally quasi- $\phi$ asymptotically nonexpansive mappings. Assume that $T_{m}$ is uniformly asymptotically regular for all $m \in \mathbb{N}^{+}$ and $F(\mathscr{T})=\bigcap_{m \in \mathbb{N}^{+}} F\left(T_{m}\right) \neq \varnothing$. Let the sequence $\left\{x_{n}\right\}$ defined by

$$
\left\{\begin{array}{l}
x_{1} \in E \text {, chosen arbitrarily; } C_{1}=C, \\
y_{n, m}=J^{-1}\left[\alpha_{n} J x_{1}+\left(1-\alpha_{n}\right) J T_{m}^{n} x_{n}\right], \\
C_{n+1}=\left\{z \in C_{n}: \sup _{m \in \mathbb{N}^{+}} \phi\left(z, J y_{n, m}\right) \leq \alpha_{n} \phi\left(z, J x_{1}\right)+\left(1-\alpha_{n}\right) \phi\left(z, J x_{n}\right)+\xi_{n}\right\}, \\
x_{n+1}=\prod_{c_{n+1}} x_{1},
\end{array}\right.
$$

where, $\xi_{n}=\mu_{n} \sup _{p \in F(\mathscr{F})} \tau\left(\phi\left(p, J x_{n}\right)\right)+\delta_{n}$ and $\left\{\alpha_{n}\right\} \subset(0,1)$. If $\lim _{n \rightarrow \infty} \alpha_{n}=0$ and $\delta_{1}=0$, then $\left\{x_{n}\right\}$ converges strongly to $\prod_{F(\mathscr{g})}^{f} x_{1}$.

Remark 3.4 The results in this paper improve and extend many recent corresponding main results of other authors (see, for example, $[3,4,7,8,10,11,15-19])$ in the following ways: (a) we introduce a new class of totally quasi-G-asymptotically nonexpansive mappings which contains the classes of the totally quasi- $\phi$-asymptotically nonexpansive mappings and many non-expansive mappings; (b) we extend from a countable family of mappings to the totally quasi-G-asymptotically nonexpansive semigroup; (c) we modify the Halpern type hybrid projection algorithm by using the generalized f-projection operator for uniformly total quasi-G-asymptotically nonexpansive semigroup. For example, Corollary 3.2 extends the main result of Seawan et al. [11] from the modified Mann type iterative algorithm to modified Halpern iterative by the generalized f-projection method. Corollary 3.3 is the main result of Chang et al.[3].

\section{Contributions}

All authors contributed equally and significantly in this research work. All authors read and approved the final manuscript.

\section{Acknowledgements}

The authors would like to thank editors and referees for many useful comments and suggestions for the improvement of the article. This study was supported by the National Natural Science Foundations of China (Grant No. 11271330) and the Natural Science Foundations of Zhejiang Province of China (Grant No. Y6110270).

\section{REFERENCES}

[1] Ya. I. Alber, C. E. Chidume and J. L. Li, "Stochastic Approximation Method for Fixed Point Problems," Applied Mathematics, Vol. 2012, No. 3, 2012, pp. 2123-2132.

[2] L. J. Chen and J. H. Huang, "Strong Convergence of an Iterative Method for Generalized Mixed Equilibrium Problems and Fixed Point Problems," Applied Mathematics, Vol. 2011, No. 2, 2011, pp. 1213-1220.

[3] S. S. Chang, L. H. W. Joseph, C. K. Chan and W. B. Zhang, "A Modified Halpern-Type Iteration Algorithm for Totally Quasi$\phi$-Asymptotically Nonexpansive Mappings with Applications," Applied Mathematics and Computation, Vol. 218, No. 11, 2012, pp. 6489-6497. http://dx.doi.org/10.1016/j.amc.2011.12.019

[4] S. S. Chang, L. H. W. Joseph, C. K. Chan and L. Yang, “ Approximation Theorems for Total Quasi- $\phi$-Asymptotically Nonexpansive Mappings with Application," Applied Mathematics and Computation, Vol. 218, No. 6, 2011, pp. 2921-2931. http://dx.doi.org/10.1016/j.amc.2011.08.036

[5] S. S. Zhang, L. Wang and Y. H. Zhao, "Multi-Valued Totally Quai-Phi-Asymptotically Nonexpansive Semigrops and Strong Convergence Theorems in Banach Spaces," Acta Mathematica Scientia, Vol. 33B, No. 2, 2013, pp. 589-599. http://dx.doi.org/10.1016/S0252-9602(13)60022-3

[6] Y. Li, "Fixed Point of a Countable Family of Uniformly Totally Quasi-Phi-Asymptotically Nonexpansive Multi-Valued Mappings in Reflexive Banach Spaces with Applications," Applied Mathematics, Vol. 2013, No. 4, 2013, pp. 6-12.

[7] X. R. Wang, S. S. Chang, L. Wang, Y. K. Tang and Y. G. Xu, "Strong Convergence Theorem for Nonlinear Operator Equa- 
tions with Total Quasi- $\phi$-Asymptotically Nonexpansive Mappings and Applications," Fixed Point Theory and Applications, Vol. 2012, 2012, p. 34. http://dx.doi.org/10.1186/1687-1812-2012-34

[8] J. Quan, S. S. Chang and X. R. Wang, "Strong Convergence for Total Quasi- $\phi$-asymptotically Nonexpansive Semigroup in Banach Spaces," Fixed Point Theory and Applications, Vol. 2012, 2012, p. 142.

[9] K. Wu and N. J. Huang, "The Generalized f-Projection Operator and an Application," Bulletin of the Australian Mathematical Society, Vol. 73, No. 2, 2006, pp. 307-317. http://dx.doi.org/10.1017/S0004972700038892

[10] X. Li, N. J. Huang and D. R. Regan, "Strong Convergence Theorems for Relatively Nonexpansive Mappings in Banach Spaces with Applications," Computers \& Mathematics with Applications, Vol. 60, No. 5, 2010, pp. 1322-1331. http://dx.doi.org/10.1016/j.camwa.2010.06.013

[11] S. Saewan, P. Kanjanasamranwong, P. Kumam and Y. J. Cho, "The Modified Mann Type Iterative Algorithm for a Countable Family of Totally Quasi- $\phi$-Asymptotically Nonexpansive Mappings by the Hybrid Generalized f-Projection Method," Fixed Point Theory and Applications, Vol. 2013, 2013, p. 63. http://dx.doi.org/10.1186/1687-1812-2013-63

[12] Y. H. Wang, "Strong Convergence Theorems for Asymptotically Weak G-Pseudo- $\varphi$-Contractive Nonself Mappings with the Generalized Projection in Banach Spaces," Abstract and Applied Analysis, Vol. 2012, 2012, Article ID: 651304.

[13] Y. H. Wang and Y. H. Xia, "Strong Convergence for Asymptotically Qseudo-Contractions with the Demiclosedness Principle in Banach Spaces," Fixed Point Theory and Applications, Vol. 2012, 2012, p. 45.

[14] K. Deimling, "Nonlinear Functional Analysis,” Sringer-Verlag, Berlin and New York, 1985. http://dx.doi.org/10.1007/978-3-662-00547-7

[15] W. Takahashi, Y. Takeuchi and R. Kubota, "Strong Convergence Theorems by Hybrid Methods for Families of Nonexpansive Mappings in Hilbert Spaces," Journal of Mathematical Analysis and Applications, Vol. 341, No. 1, 2008, pp. $276-286$. http://dx.doi.org/10.1016/j.jmaa.2007.09.062

[16] S. Saewan, P. Kumam and K. Wattanawitoon, "Convergence Theorem Based on a New Hybrid Projection Method for Finding a Common Solution of Generalized Equilibrium and Variational Inequality Problems in Banach Spaces," Abstract and Applied Analysis, Vol. 2010, 2010, Article ID: 734126. http://dx.doi.org/10.1155/2010/734126

[17] X. L. Qin, Y. J. Cho, S. M. Kang and H. Y. Zhou, "Convergence of a Modified Halpern-Type Iterative Algorithm for Quasi- $\phi$ Nonexpansive Mappings,” Applied Mathematics Letters, Vol. 22, No. 7, 2009, pp. 1051-1055. http://dx.doi.org/10.1016/j.aml.2009.01.015

[18] Y. F. Su, H. K. Xu and X. Zhang, "Strong Convergence Theorems for Two Countable Families of Weak Relatively Nonexpansive Mappings and Applications," Nonlinear Analysis, Vol. 73, No. 12, 2010, pp. 3890-3906. http://dx.doi.org/10.1016/j.na.2010.08.021

[19] Z. M. Wang, Y. F. Su, D. X. Wang and Y. C. Dong, "A Modified Halpern-Type Iteration Algorithm for a Family of HemiRelative Nonexpansive Mappings and Systems of Equilibrium Problems in Banach Spaces," Journal of Computational and Applied Mathematics, Vol. 235, No. 8, 2011, pp. 2364-2371. http://dx.doi.org/10.1016/j.cam.2010.10.036 